\title{
Anaesthetic management of Ludwig's angina in a full term pregnant patient
}

\author{
SM Bandishte ${ }^{1^{*}}$, MC Patil ${ }^{2}$ \\ Assistant Professor ${ }^{1}$, Professor ${ }^{2}$, Department of Anaesthesiology, JN Medical College, Belagavi, \\ Karnataka, India.
}

\begin{abstract}
We report a case of drainage of Ludwig's angina in a pregnant patient conducted under general anaesthesia using awake fibreoptic intubation with least possible anaesthetic drugs.
\end{abstract}

Keywords: Ludwig's angina; pregnant patient; difficult airway; awake fibreoptic intubation; minimum anaesthetic drugs

\section{Introduction}

Ludwig's angina is a rapidly progressing cellulitis of the submandibular space causing trismus along with oedema and induration of the sublingual and submandibular spaces leading to difficult airway. ${ }^{1}$ In adults, the common presenting complaints in Ludwig's angina are odynophagia, dysphagia, fever, neck pain, swelling, trismus, and respiratory distress. ${ }^{2}$ Ludwig's angina in pregnant patients is a rare case. Anaesthetic management can be regional or general anaesthesia or elective tracheostomy. ${ }^{3-6}$ Awake fibreoptic intubation in skilled hands is considered the gold standard.

\section{Case report}

A 20-year-old female presented to the emergency department with rapidly increasing swelling over right cheek since four days. Patient was 36 weeks pregnant. A diagnosis of Ludwig's angina was made.

Local examination showed that the swelling extended from right infraorbital margin to right inferior border of mandible, right angle of mouth to right angle of mandible. Swelling was soft and tender on palpation. Airway assessment revealed mouth opening of 1 finger.

Mallampati grading was not possible (Figure 1).

Dental caries was noted however no loose or missing teeth were present. Systemic examination

*Correspondence: SM Bandishte

E mail: drsagaranaesthetist@gmail.com

D 0000-0002-4057-8638

Received: $30 / 01 / 2017$

Accepted: 07/05/2017

DOI: 10.4038 /slja.v25i2.8209

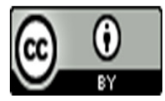

was normal. Obstetric examination revealed a single live intra uterine pregnancy with approximately 36 weeks gestational age.

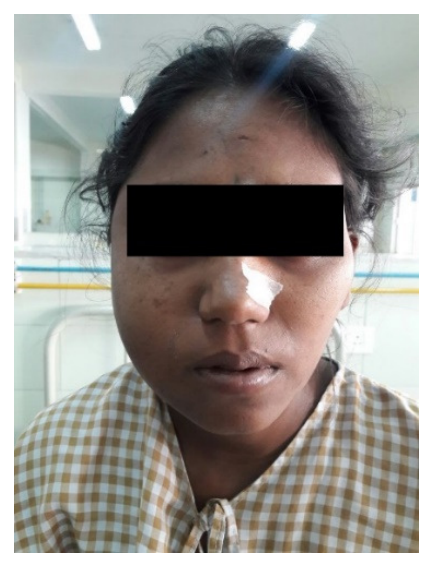

Figure 1

Patient had a haemoglobin of $8.4 \mathrm{~g} \%$ and total leucocyte count $18,700 / \mathrm{cm}^{3}$. Other routine laboratory tests were normal. Ultrasound of neck showed ill-defined hypoechoic collection deep to the submandibular gland measuring $27 \times 12 \mathrm{~mm}$ approximately. Indirect laryngoscopy showed normal movement of vocal cords with phonation. Patient was scheduled for drainage of the abscess. Plan of anaesthesia was to give general anaesthesia using awake fibreoptic intubation with a cuffed red rubber tube using least possible number of anaesthetic drugs. Procedure was explained to the patient along with all the risks involved including need for an emergency tracheostomy. Appropriate consent was taken. Patient was kept fasting for six hours prior to surgery. 18G intravenous (IV) cannula was secured. Intramuscular (IM) glycopyrrolate $5 \mu \mathrm{g} / \mathrm{kg}$ was given. Ranitidine 1 $\mathrm{mg} / \mathrm{kg}$ and ondansetron $0.08 \mathrm{mg} / \mathrm{kg}$ i.v. was given. Topical $4 \%$ lignocaine in saline was nebulized. 
In the operating room, crash cart and suction were kept ready. Flexible fibreoptic laryngoscope (FFL) was assembled and a cuffed red rubber endotracheal tube (ETT) size 6 was mounted on the FFL. Standard monitors pulse-oximeter $\left(\mathrm{SpO}_{2}\right)$, ECG, non-invasive blood pressure (NIBP) and temperature were attached. An obstetrician was monitoring fetal heart sounds (FHS) by cardiotocogram. $10 \%$ topical lignocaine was sprayed on the oropharynx. Transtracheal block was given using $3 \mathrm{ml}$ of $2 \%$ lignocaine. FFL was advanced through the right nostril till carina was visualized. The ETT was railroaded over the FFL. Bain's circuit was connected and $100 \%$ oxygen was delivered at 8 litres/min. ETT position was confirmed by ensuring bilateral equal air entry and capnography and fixed in position. Anaesthesia was induced with propofol $2 \mathrm{mg} / \mathrm{kg}$ and atracurium 0.5 $\mathrm{mg} / \mathrm{kg}$ i.v. After induction, HR was $82 / \mathrm{min}$, NIBP $130 / 84 \mathrm{mmHg}, \mathrm{SpO}_{2} 100 \%, \mathrm{EtCO}_{2} 32 \mathrm{mmHg}$ and FHS 132 beats/min.

Anaesthesia was maintained using a mixture of $\mathrm{O}_{2}: \mathrm{N}_{2} \mathrm{O}$ (50:50) with intermittent intravenous boluses of propofol and atracurium as needed. 500mg paracetamol i.v.was given. Dexamethasone $0.2 \mathrm{mg} / \mathrm{kg}$ was given i.v. to prevent airway oedema. Surgical procedure lasted for $45 \mathrm{~min}$. Vital parameters remained stable throughout the procedure.

On completion of the procedure glycopyrrolate 10 $\mu \mathrm{g} / \mathrm{kg}$ and neostigmine $0.05 \mathrm{mg} / \mathrm{kg}$ were given i.v.to reverse the anaesthesia. After extubation HR was $92 / \mathrm{min}$, NIBP $130 / 90 \mathrm{mmHg}, \mathrm{SpO}_{2} 99 \%$ on room air and FHS 134 beats/min.

\section{Discussion}

We present a case of Ludwig's angina in a patient who was 36 weeks pregnant for abscess drainage under general anaesthesia. Such cases have a high mortality ranging from $8-25 \% .^{7,8}$ Pregnancy with its anatomical and physiological changes makes the airway management further difficult. Also, CT scan is contraindicated in pregnancy due to which, extent of the infection cannot be assessed with certainty adding to the difficulty in airway management. Direct laryngoscopy and endotracheal intubation is difficult due to altered airway anatomy. Because of these difficulties, previously similar cases in pregnant women have been operated under local anaesthesia. ${ }^{3,4,9}$ However, it has been reported that regional anaesthesia was inadequate, leading to significant pain, hence conversion to general anaesthesia. ${ }^{4}$ Therefore in such cases, the safest option is to secure the airway while the patient remains awake. Furthermore laryngospasm leading to asphyxia and death have been reported following incision and drainage of Ludwig's angina under local anaesthesia. ${ }^{8}$

\section{Conclusion}

We managed drainage of Ludwig's angina in a full term pregnant patient under general anaesthesia using awake fibreoptic nasal intubation.

\section{References}

1. Hasan S, Asif S, Quadri S. Ludwig's angina - an alarming multidisciplinary challenge - overview of literature UJP 2013;02(05): page 1-44.

2. Larawin V, Naipao J, Dubey SP. Head and neck space infections. Otolaryngol Head Neck Surg. 2006;135(6):889-893.

https://doi.org/10.1016/j.otohns.2006.07.007 PMid:17141079

3. Gupta AK, Dhulkhed VK, Rudagi BM, Gupta A. Drainage of Ludwig's angina in a pregnant patient under superficial cervical plexus block. Anaesth Pain \& Intensive Care 2009; 13: 68-70.

4. Desai S, Ladhad D. Awake Fibreoptic Intubation for the Drainage of Ludwig's Angina in a Pregnant Patient; A Case Report. J AnesthClin Res 2015;6: 550.

5. Potter JK, Herford AS, Ellis E III. Tracheostomy versus endotracheal intubation for airway management in deep neck infections. $\mathrm{J}$ oral maxillofacsurg2002;60:349-54. https://doi.org/10.1053/joms.2002.31218

6. Nagaria A, Malliwal A. Indian Journal of Basic and Applied Medical Research; March 2015; 4(2): 266269

7. Osunde O, Bassey G, Ver-Or N. Management of Ludwig's Angina in Pregnancy: Review of 10 Cases. Ann Med Health Sci Res 2014;4:361-364. https://doi.org/10.4103/2141-9248.133460 PMid:24971209 PMCid:PMC4071734

8. Ugboko V, Ndukwe K, Oginni F. Ludwig's angina: an analysis of sixteen cases in a suburban nigerian tertiary facility. African Journal of oral Health 2005; 2: 16-23.

9. Soltero R, Mercado-Alvarado J. Successful conservative management of Ludwig's angina in advanced pregnancy. BolAsoc Med PR 2009; 101: 42-43.

PMid:20120985 